\title{
Expression of the Immunohistochemical Markers p16 and Ki-67 and Their Usefulness in the Diagnosis of Cervical Intraepithelial Neoplasms
}

\section{Reprodutibilidade do diagnóstico das neoplasias intraepiteliais cervicais e a influência dos marcadores imuno-histoquímicos p16 e Ki-67 como ferramentas auxiliares}

Fernanda Lopes Pontes de Melo ${ }^{1}$ Carmen Lúcia Penteado Lancellotti ${ }^{2}$ Maria Antonieta Longo Galvão da Silva ${ }^{3}$

\footnotetext{
${ }^{1}$ Master's Program in Health Sciences, School of Medical Sciences, Santa Casa de São Paulo, São Paulo, SP, Brazil

2 Pathological Anatomy Course, School of Medical Sciences, Santa Casa de São Paulo, São Paulo, SP, Brazil

3 Pathological Anatomy Course, School of Medical Sciences, Santa Casa de São Paulo, São Paulo, SP, Brazil
}

\begin{abstract}
Address for correspondence Fernanda Lopes Pontes de Melo, MD, Pathological Anatomy Service, Irmandade da Santa Casa de Misericórdia de São Paulo Central Hospital, Rua Doutor Cesário Mota Júnior, 112 - Vila Buarque, São Paulo, SP 01221-020, Brazil (e-mail: fernandapontes@gmail.com).
\end{abstract}

Rev Bras Ginec Obst 2016;38:82-87.

received July 10, 2015 accepted November 19, 2015 published online February 3, 2016
Objective The aim of this study was to determine the expression of the immunohistochemical markers p16 and $\mathrm{K}_{\mathrm{i}}-67$ in cervical intraepithelial neoplasms and their influence on the level of agreement among different observers and for the same observer.

Methods The study included 184 patients with cervical intraepithelial neoplasms previously confirmed through biopsies performed between 2005 and 2006. Three pathologists reviewed the biopsies by using hematoxylin-eosin staining to reach a consensus on the diagnosis. Subsequently, an immunohistochemical study analyzed the expression of $\mathrm{p} 16$ and $\mathrm{K}_{\mathrm{i}}-67$ in such cases.

Results The comparison among the reviewing pathologists revealed only moderate agreement (kappa $=0.44)$. The agreement improved when the differentiation of highgrade lesions (cervical intraepithelial neoplasm - CIN - 3) was analyzed (kappa $=0.59$ ). p16 staining exhibited a high negative predictive value and sensitivity; however, the specificity was low. Overall, both qualitative and quantitative analyses of $\mathrm{p} 16$ and a quantitative analysis $\mathrm{K}_{\mathrm{i}}-67$ exhibited low accuracy. The agreement among diagnoses before immunohistochemistry was 0.47 . The use of immunohistochemistry increased the agreement to 0.68 .

- $\mathrm{K}_{\mathrm{i}-67}$

- kappa

Copyright $(2016$ by Thieme Publicações License terms Ltda, Rio de Janeiro, Brazil
(®) $\Theta \circledast$ 


\section{Resumo}

\author{
Palavras -chave \\ - neoplasia \\ intraepitelial \\ cervical \\ - HPV \\ - p16 \\ - $\mathrm{K}_{\mathrm{i}}-67$ \\ - kappa
}

Conclusion Our study showed that the agreement among observers using traditional diagnostic criteria of cervical intraepithelial lesions can improve with the use of immunohistochemistry.

Objetivo Observar a expressão dos marcadores imuno-histoquímicos p 16 e $\mathrm{K}_{\mathrm{i}}-67$ em neoplasias intraepiteliais cervicais e sua influência na concordância entre observadores diferentes e, entre o mesmo observador.

Métodos Foram incluídas no estudo 184 pacientes com neoplasias cervicais intraepiteliais confirmadas por biópsia realizadas durante os anos de 2005 e 2006. As biópsias foram revistas, primeiramente, por três patologistas utilizando-se apenas a coloração de Hematoxilina-Eosina. Foi realizado um consenso acerca do diagnóstico. Posteriormente, foi realizado o estudo imuno-histoquímico e analisada a expressão de p16 e $\mathrm{K}_{\mathrm{i}}$ 67 nesses casos.

Resultados A comparação entre os patologistas revisores mostrou uma concordância apenas regular $(k=0,44$. A concordância foi melhor quando analisada apenas a capacidade de diferenciar lesões de alto grau (NIC 3) $(k=0,59)$. A marcação de p16 mostrou alto valor preditivo negativo e sensibilidade, porém baixa especificidade. Em geral, tanto p16 qualitativo, quanto p16 quantitativo e $\mathrm{K}_{\mathrm{i}}-67$ quantitativo mostraram baixa acurácia geral. A concordância entre os diagnósticos antes da imuno-histoquímica obteve $k=0,47$, e após o auxílio da imuno-histoquímica houve um aumento do Kappa para 0,68. A marcação de p16 mostrou alto valor preditivo negativo e sensibilidade, porém baixa especificidade. Em geral, tanto p16 qualitativo, quanto p16 quantitativo e $\mathrm{K}_{\mathrm{i}}-67$ quantitativo mostraram baixa acurácia geral.

Conclusão Nosso estudo mostrou que a concordância no diagnóstico tradicional de lesões intraepiteliais cervicais é regular e que pode ser melhorada como o auxílio da imuno-histoquímica.

\section{Introduction}

Every year, there are $\sim 500,000$ new cases of uterine cervical cancers in women worldwide. In 2012, 265,000 deaths were reported. In Brazil, uterine cervical cancer is the third most frequent cancer among women (not considering non-melanoma skin cancer). ${ }^{1}$ Approximately $80 \%$ of deaths could be prevented by screening for precursor lesions in women 25 to 65 years of age. ${ }^{2}$

Histopathological examination is the gold standard for a proper intraepithelial neoplasm diagnosis, and this technique is used to determine the best treatment for uterine cervical cancer patients. The reproducibility of the diagnosis is crucial. However, clinical studies have shown that the reproducibility of cervical biopsy interpretations is, at most, moderate. ${ }^{3,4}$ Multiple factors not related to the human papilloma virus (HPV), such as atrophy, immature metaplasia, and reactive/inflammatory atypia can change cervical mucus. Indeed, these conditions can simulate cervical squamous intraepithelial neoplasms and cause discrepancies even among experienced pathologists. ${ }^{5-7}$

The literature suggests that the regular use of immunohistochemical markers, such as $\mathrm{p} 16$ and $\mathrm{K}_{\mathrm{i}}-7$, can improve diagnostic reproducibility. ${ }^{7-12}$
Thus, the present study investigated the relationship between the expression of the immunohistochemical markers p16 and $\mathrm{K}_{\mathrm{i}}-67$ and the grade of cervical intraepithelial neoplasms. In addition, we determined the usefulness of these markers as auxiliary pathologist tools to detect highrisk cases with an improved degree of agreement.

\section{Methods}

We retrospectively analyzed surgical uterine cervical samples obtained at the Pathological Anatomy Service of Santa Casa de Misericórdia de São Paulo, São Paulo, Brazil, between 2005 and 2006. These samples were previously diagnosed as positive for cervical intraepithelial neoplasia. The material used was derived from tissue removed by incisional and excisional biopsies (loop electrosurgical excision procedure (LEEP) and hysterectomies), fixed in $10 \%$ formalin and embedded in paraffin. Three pathologists reviewed the cases first independently and then jointly by using only hematoxylin-eosin staining. We used the independent diagnoses from each pathologist to analyze inter-observer agreement. The result of the joint analysis by the three pathologists was defined as the consensus diagnosis and considered to be the gold standard. Subsequently, samples stained with 
hematoxylin-eosin and samples that underwent immunohistochemistry were analyzed together.

The paraffin blocks were manually cut using a microtome, and sections were stained with hematoxylin-eosin. Histological sections were placed on silanized slides for immunohistochemistry with the markers p16 (p16 INK4a, clone G175-405, Zeta) and $\mathrm{K}_{\mathrm{i}}-67$ (clone MIB-1, Dako). Immunohistochemistry was performed using the streptavidin-biotinperoxidase technique following the manufacturer's instructions and routine immunohistochemistry protocols of the Pathological Anatomy Service of Santa Casa de São Paulo.

We assessed p16 staining using two methods: qualitative and quantitative. The qualitative method was based on Lesnikova et al. ${ }^{8}$ The sample was considered positive if at least $10 \%$ of the epithelial cells surrounding the lesion showed nuclear and/ or cytoplasmic expression (starting from the basal/parabasal layer and variably extending to the intermediate and superficial layers). The sample was defined as negative if the p16 expression was less than $10 \%$. The quantitative method was based on Nam et al. ${ }^{13}$ Samples were defined as Grade 0 when less than $1 \%$ of the epithelial cells surrounding the lesion were positive for p16, Grade 1 when 1 to $5 \%$ of the epithelial cells were positive for p 16 , Grade 2 when 5 to $25 \%$ of the cells were positive for p16, and Grade 3 when over $25 \%$ of the cells surrounding the lesion were positive.

$\mathrm{K}_{\mathrm{i}}-67$ staining was evaluated quantitatively according to Nam et al. ${ }^{13}$ The samples were defined as Grade 1 when less than $5 \%$ of the epithelial cell nuclei stained positive for $K_{i}-67$, Grade 2 when 5 to $30 \%$ of the epithelial cell nuclei stained positive for $\mathrm{K}_{\mathrm{i}}-67$, and Grade 3 when the nuclear positivity was greater than $30 \%$.

\section{Statistical Analysis}

To determine the rates of agreement (original diagnosis, reviewing pathologists, and consensus), we used the Kappa test to examine the results of the same diagnostic test across different individuals and diagnoses provided by the same individual at different times. The data are described as a simple agreement rate (the percentage of diagnoses that were similar), which we evaluated using the kappa statistic and its confidence interval and p-value. The confidence interval was $95 \%$, and p-values $<0.05$ were considered statistically significant.

The consensus diagnosis was considered the gold standard for all analyses. The Kappa test requires symmetric contingency tables; thus, the cases diagnosed as metaplasia were excluded from the analysis between the original diagnosis and that of each reviewing pathologist or the consensus.

To evaluate the agreement among observers, comparisons between cervical intraepithelial neoplasia (CIN) groups included metaplasia versus CIN 1, CIN 2, or CIN 3 and CIN 3 versus the other diagnoses. There were no asymmetry problems with the contingency tables after grouping.

We assessed the value of immunohistochemical markers as independent diagnostic criteria by calculating the sensitivity, specificity, positive predictive value, negative predictive value, and accuracy of each marker to properly diagnose CIN 3 when compared with the consensus diagnosis.
The influence of the immunohistochemical markers on the rate of agreement between each pathologist and the consensus was calculated by directly comparing the kappa agreement rates. We then compared the diagnoses reported by the pathologist with and without the use of immunohistochemistry. The cases without immunohistochemical data or previous and consensus diagnoses were not included in the final analysis. The calculations were performed using SPSS 15.0 for Windows.

The Ethics Committee of the Hospital Santa Casa de Misericórdia de São Paulo approved this study.

\section{Results}

A total of 184 cases of cervical intraepithelial neoplasms were included in the study. According to the original diagnosis, 41 cases were CIN 1, 59 cases were CIN 2, and 84 cases were CIN 3. The age of patients ranged from 16 to 81 years, and the mean and median ages were 36 and 38 years, respectively. The age distribution of the group consisted of $17 \%$ of patients between 16 and 25 years of age, $47 \%$ of patients between 26 to 40 years of age, $28 \%$ of patients between 41 to 60 years of age, and $8 \%$ of patients over 60 years of age. The analyzed material was a biopsy in $61 \%$ of cases, an electrosurgical excision in $37 \%$ of cases, and a surgical specimen (cervix and uterus) in $2 \%$ of cases. Immunohistochemical reactions were performed in 153 cases. Total 31 cases were excluded from the analysis because the material was insufficient to complete the experiment. Because of these limitations, we only calculated the agreement rate before and after access to the immunohistochemical markers for Pathologist 1.

For Pathologist 1, 18\% of the cases were CIN 1, 17\% of the cases were CIN 2, 38\% of the cases were CIN 3, and $27 \%$ of the cases were metaplasia. Pathologist 2 defined $11 \%$ of the cases as CIN $1,28 \%$ of the cases as CIN 2, and $21 \%$ of the cases as CIN 3. Pathologist 2 classified $37 \%$ of the cases as metaplasia. Pathologist 3 characterized 15\% of the cases as CIN 1, 24\% of the cases as CIN 2, 35\% of the cases as CIN 3, and 26\% of the cases as metaplasia. The mean kappa agreement rate among the pathologists was $0.44(0.36-0.51)$. This kappa value corresponds to moderate agreement. There was disagreement between the original and consensus diagnoses in 43\% of cases and a fair kappa agreement rate of 0.33 (95\% CI 0.18 $0.48, p<0.01$ ).

The general rate of agreement was higher for the cases divided into metaplasia and CIN 1 versus CIN 2 and CIN 3. The agreement between the consensus diagnosis and the original diagnosis was $71 \%$ with a kappa of 0.41 .

The agreement rate was good for the cases divided into CIN 3 and non-CIN 3 based on the consensus diagnosis. The kappa value for the agreement between the original diagnosis and the consensus diagnosis was 0.37 (95\% CI $0.24-0.51$, $p<0.01$ ).

\section{Results Based on Immunohistochemistry}

A total of $54.2 \%$ of cases were positive for p16. Out of this 54.2\%, 38 cases were identified as CIN 3 (-Fig. $\mathbf{1}$ ), 31 cases 


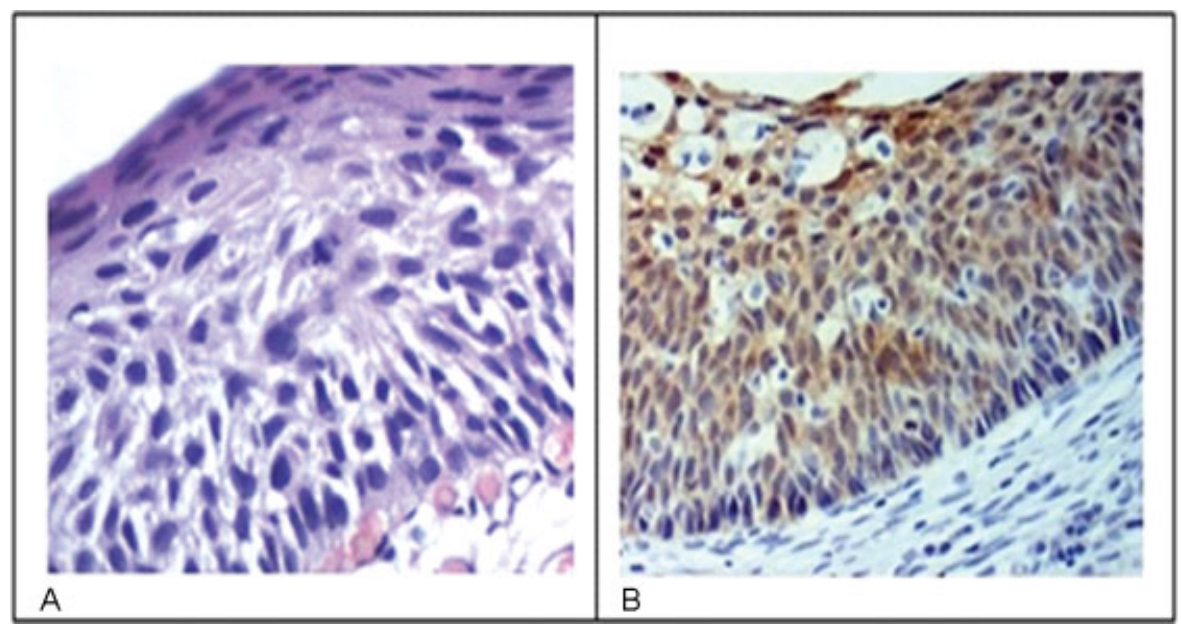

Fig. 1 A uterine cervix exhibited a cervical intraepithelial neoplasm (CIN 3) with hematoxylin-eosin staining (A) and showed diffuse staining with a p16 antibody (B).

were identified as CIN 2, 6 cases were identified as CIN 1, and 8 cases were characterized as metaplasia.

Only two cases of CIN 3 and 6 cases of CIN 2 were characterized by low $\mathrm{K}_{\mathrm{i}}-67$ expression (grade 1 ). No cases of CIN 1 and one case of metaplasia were characterized by high $\mathrm{K}_{\mathrm{i}}-67$ expression (Grade 3).

Overall, the immunohistochemical markers showed moderate accuracy as independent diagnostic tests for the diagnosis of CIN 3. The accuracy ranged from 70 to $83 \%$. Notably, none of the markers achieved satisfactory rates of both sensitivity and specificity (-Table $\mathbf{1}$ ).

The agreement rate before and after immunohistochemistry was low. The pathologist diagnoses before and after immunohistochemistry remained the same in $56 \%$ of cases. The kappa agreement rate was 0.39 (95\% CI 0.29 - 0.49, $p<0.01$ ).

The agreement rate between the pathologist and the consensus increased from $61 \%$ (kappa $=0.47,95 \% \mathrm{CI} 0.38-0.56$, $p<0.01$ ) to $77 \%$ (kappa $=0.68,95 \% \mathrm{CI} 0.60-0.77, p<0.01$ ) with the aid of immunohistochemistry (-Tables 2 and $\mathbf{3}$ ).

\section{Discussion}

Our study confirmed that the reproducibility of traditional pathological examination is not satisfactory for determining the grade of cervical intraepithelial neoplasms. Both the agreement among three pathologists and the agreement between the original and consensus diagnoses ranged from moderate to fair (kappa $=0.44$ and 0.33 , respectively). The rate of agreement among each reviewing pathologist and the consensus was moderate (kappa $=0.60)$ and higher than other comparisons. This result may be explained by the use of the same pathologists for individual and consensus diagnoses.

The largest study of the reproducibility of cervical intraepithelial neoplasia diagnoses reviewed 6272 cases that were diagnosed by non-specialist pathologists. ${ }^{14}$ Each case was reviewed by one of three teaching gynecopathologists. The agreement rate for that study (0.46) synthesizes the agreement among non-specialists and more experienced pathologists from reference centers in the absence of biases that could affect the results.

Our results confirm the literature data that showed reproducibility rates at the lower limit of moderate agreement.

Many studies show that the primary difficulty is the diagnostic reproducibility in intermediate cases; indeed, the agreement rates for CIN 2 cases are the lowest and negatively affect all statistical parameters. ${ }^{3,15}$

In our study, we found a slightly improved kappa value of 0.33 for the agreement between the original diagnosis and the consensus diagnosis when the cases were divided into two categories rather than into four. When we used CIN 2 as

Table 1 Potential immunohistochemical markers for a CIN 3 diagnosis

\begin{tabular}{|l|l|l|l|}
\hline & \multicolumn{3}{|l|}{ Marker } \\
\hline & Qualitative p16 (\%) & Quantitative p16 (\%) & Quantitative $\mathrm{K}_{\mathrm{i}}$-67 (67\%) \\
\hline Sensitivity & 97.4 & 79.5 & 53.8 \\
\hline Specificity & 60.5 & 84.4 & 87.7 \\
\hline Positive predictive value & 45.8 & 63.3 & 60.0 \\
\hline Negative predictive value & 98.6 & 92.3 & 84.7 \\
\hline Accuracy & 70.0 & 83.0 & 79.0 \\
\hline
\end{tabular}

The cases with a high degree of staining (grade 3) were used to calculate the quantitative p16 and $\mathrm{K}_{\mathrm{i}}-67$ data. 
Table 2 The agreement between pathologists without the use of immunohistochemistry

\begin{tabular}{|c|c|c|c|c|c|c|}
\hline & \multirow[b]{2}{*}{ Number of cases } & \multicolumn{4}{|c|}{ Consensus } & \multirow[t]{2}{*}{ Total } \\
\hline & & CIN 1 & CIN 2 & CIN 3 & Metaplasia & \\
\hline \multirow[t]{4}{*}{ Pathologist before immuno } & CIN 1 & 12 & 3 & 0 & 17 & 32 \\
\hline & CIN 2 & 5 & 15 & 2 & 6 & 28 \\
\hline & CIN 3 & 2 & 20 & 40 & 2 & 64 \\
\hline & Metaplasia & 5 & 3 & 1 & 37 & 46 \\
\hline \multicolumn{2}{|l|}{ Total } & 24 & 41 & 43 & 62 & 170 \\
\hline
\end{tabular}

Abbreviation: CIN, cervical intraepithelial neoplasm; immuno, immunohistochemistry.

Kappa $=0.47(95 \% \mathrm{Cl} 0.38-0.56), p<0.01$.

Table 3 The agreement between pathologists using immunohistochemistry for p16 and $\mathrm{K}_{\mathrm{i}-67}$

\begin{tabular}{|c|c|c|c|c|c|c|}
\hline & \multirow[b]{2}{*}{ Number of cases } & \multicolumn{4}{|c|}{ Consensus } & \multirow[t]{2}{*}{ Total } \\
\hline & & CIN 1 & CIN 2 & CIN 3 & Metaplasia & \\
\hline \multirow[t]{4}{*}{ Pathologist after immuno } & CIN 1 & 19 & 0 & 1 & 8 & 28 \\
\hline & CIN 2 & 1 & 21 & 3 & 3 & 28 \\
\hline & CIN 3 & 0 & 14 & 35 & 3 & 52 \\
\hline & Metaplasia & 0 & 2 & 0 & 43 & 45 \\
\hline \multicolumn{2}{|l|}{ Total } & 20 & 37 & 39 & 57 & 153 \\
\hline
\end{tabular}

Kappa $=0.68(95 \%$ Cl $0.60-0.77), p<0.01$.

the cut-off, the kappa value increased to 0.41 , and when we used CIN 3 as the cut-off, the kappa value increased to 0.37 . Similarly, the mean kappa value between the pathologist's and the consensus diagnoses was 0.60 for four categories. The kappa value increased to 0.78 with CIN 2 as the cut-off and 0.67 with CIN 3 as the cut-off.

The immunohistochemical analysis revealed an expected staining pattern. The staining percentage of each CIN grade was comparable with the values found in the literature. However, a simple comparison between values should be performed with caution because the criteria used to define positive cases vary greatly among studies. Some studies use the presence of any staining as a positivity criterion, even if the staining is focal and limited. ${ }^{16}$ Other studies characterize a positive case by continuous staining throughout the epithelium. ${ }^{17}$ Genovés et al ${ }^{18}$ and Nishio et al ${ }^{19}$ considered both moderate and diffuse staining as a positive marker. $\mathrm{K}_{\mathrm{i}}-67$ values vary greatly in the literature and exhibit the same methodological issues in the definition of positivity, which hinders the ability to directly compare values.

The analysis of immunohistochemical markers has a certain degree of subjectivity; thus, this method does not provide completely objective observations. The level of agreement among observers differs when a specific degree of p16 staining is defined as positive (positive is defined as a strong and diffuse staining in most studies). Galgano et $\mathrm{al}^{5}$ reported an agreement rate of 0.87 among observers when defining strong and diffuse p16 staining as positive.

Our study shows that $\mathrm{p} 16$ and $\mathrm{K}_{\mathrm{i}}-67$ expressions in cervical intraepithelial neoplasms are more common in high-grade lesions. These immunohistochemical markers do not exhibit adequate accuracy as independent diagnostic markers. However, the negative predictive value of p16 was a useful tool for the identification of cases that required more attention. The kappa agreement rate between the pathologist and the consensus increased from 0.47 to a strong agreement value of 0.68 . Our study confirms that the level of reproducibility of the conventional diagnosis of cervical intraepithelial neoplasms is fair; however, the diagnosis can be improved with the use of immunohistochemistry.

Conflict of Interest

The authors declare no conflict of interest in conducting this study.

\section{Acknowledgments}

The authors acknowledge the Coordenação de Aperfeiçoamento de Pessoal de Nível Superior - Capes.

\section{Referências}

1 -. Brasil. Ministério da Saúde. Instituto Nacional de Câncer José Alencar Gomes da Silva. Estimativa 2014: incidência de câncer no Brasil. Rio de Janeiro: INCA; 2014

2 Arbyn M, Anttila A, Jordan J, et al. European guidelines for quality assurance in cervical cancer screening. Ann Oncol 2010;21(3): 448-458

3 Stoler MH, Schiffman M; Atypical Squamous Cells of Undetermined Significance-Low-grade Squamous Intraepithelial Lesion Triage Study (ALTS) Group. Interobserver reproducibility of cervical 
cytologic and histologic interpretations: realistic estimates from the ASCUS-LSIL Triage Study. JAMA 2001;285(11):1500-1505

4 Mittal S, Ghosh I, Banerjee D, et al. Reproducibility of cervical intraepithelial neoplasia diagnosis on histological review of cervical punch biopsies from a visual inspection with acetic acid and HPV detection-based screening program. Int J Gynaecol Obstet 2014;126(3):227-231

5 Galgano MT, Castle PE, Atkins KA, Brix WK, Nassau SR, Stoler MH. Using biomarkers as objective standards in the diagnosis of cervical biopsies. Am J Surg Pathol 2010;34(8):1077-1087

6 Darragh TM, Colgan TJ, Cox JT, et al; Members of LAST Project Work Groups. The lower anogenital squamous terminology standardization project for HPV-associated lesions: background and consensus recommendations from the College of American Pathologists and the American Society for Colposcopy and Cervical Pathology. Arch Pathol Lab Med 2012;136(10):1266-1297

7 - Dabbs DJ. Diagnostic immunohistochemistry: theranostic and genomic applications, 2nd ed. Philadelphia: Elsevier; 2006

8 Lesnikova I, Lidang M, Hamilton-Dutoit S, Koch J. p16 as a diagnostic marker of cervical neoplasia: a tissue microarray study of 796 archival specimens. Diagn Pathol 2009;4:22

9 Cardoso FA, Campaner AB, Silva MA. Prognostic value of p16 (INK4a) as a marker of clinical evolution in patients with cervical intraepithelial neoplasia grade 3 (CIN 3) treated by cervical conization. APMIS 2014;122(3):192-199

10 Reuschenbach M, Seiz M, von Knebel Doeberitz C, et al. Evaluation of cervical cone biopsies for coexpression of p16INK4a and Ki-67 in epithelial cells. Int J Cancer 2012;130(2):388-394

11 Carozzi F, Gillio-Tos A, Confortini M, et al; NTCC working group. Risk of high-grade cervical intraepithelial neoplasia during follow-up in HPV-positive women according to baseline p16-INK4A results: a prospective analysis of a nested substudy of the NTCC randomised controlled trial. Lancet Oncol 2013;14(2):168-176
12 Malpica A, Matisic JP, Niekirk DV, et al. Kappa statistics to measure interrater and intrarater agreement for 1790 cervical biopsy specimens among twelve pathologists: qualitative histopathologic analysis and methodologic issues. Gynecol Oncol 2005;99(3, Suppl 1):S38-S52

13 Nam EJ, Kim JW, Hong JW, et al. Expression of the p16 and Ki-67 in relation to the grade of cervical intraepithelial neoplasia and high-risk human papillomavirus infection. J Gynecol Oncol 2008; 19(3):162-168

14 Stoler MH, Ronnett BM, Joste NE, Hunt WC, Cuzick J, Wheeler CM; New Mexico HPV Pap Registry Steering Committee. The interpretive variability of cervical biopsies and its relationship to HPV status. Am J Surg Pathol 2015;39(6):729-736

15 Cai B, Ronnett BM, Stoler M, et al. Longitudinal evaluation of interobserver and intraobserver agreement of cervical intraepithelial neoplasia diagnosis among an experienced panel of gynecologic pathologists. Am J Surg Pathol 2007;31(12):1854-1860

16 Reuschenbach M, Wentzensen N, Dijkstra MG, von Knebel Doeberitz M, Arbyn M. p16INK4a immunohistochemistry in cervical biopsy specimens: A systematic review and metaanalysis of the interobserver agreement. Am J Clin Pathol 2014;142(6):767-772

17 Liao GD, Sellors JW, Sun HK, et al. p16INK4A immunohistochemical staining and predictive value for progression of cervical intraepithelial neoplasia grade 1: a prospective study in China. Int J Cancer 2014;134(7):1715-1724

18 Genovés J, Alameda F, Mancebo G, et al. Human papillomavirus detection and p16INK4a expression in cervical lesions: a comparative study. Hum Pathol 2014;45(4):826-833

19 Nishio S, Fujii T, Nishio H, et al. p16(INK4a) immunohistochemistry is a promising biomarker to predict the outcome of low grade cervical intraepithelial neoplasia: comparison study with HPV genotyping. J Gynecol Oncol 2013;24(3):215-221 